\title{
Longitudinal Characteristics of T Cell Responses in Asymptomatic SARS-CoV-2 Infection
}

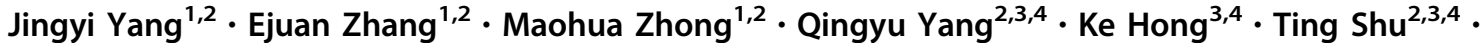

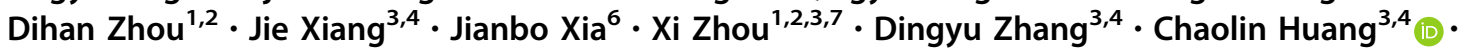 \\ You Shang ${ }^{3,4,5}$ (1) $\cdot$ Huimin Yan $^{1,2,7}$
}

Received: 28 June 2020 / Accepted: 24 July 2020 / Published online: 21 August 2020

(c) Wuhan Institute of Virology, CAS 2020

Dear Editor,

SARS-CoV-2 causes a spectrum of illness, ranging from an asymptomatic state to life-threatening multi-organ failure, and imposes a high socioeconomic burden on its sufferers and on society (Chen et al. 2020; Pan et al. 2020). Asymptomatic SARS-CoV-2 infection, confirmed by assay with quantitative real-time reverse transcription PCR (qRT-PCR), presented neither clinical symptom nor radiographic abnormality (Pan et al. 2020). While T cell responses are crucial for viral control, viral infection also induces significant count decrease and function impairment of T cells (Chen et al. 2020; Qin et al. 2020). Despite high rate of SARS-CoV-2 asymptomatic infections (Black et al. 2020), T cell responses of this population are still largely unknown. Here, we reported the kinetics of $\mathrm{CD}^{+}$and

Jingyi Yang, Ejuan Zhang and Maohua Zhong have contributed equally to this work.

Electronic supplementary material The online version of this article (https://doi.org/10.1007/s12250-020-00277-4) contains supplementary material, which is available to authorized users.

\footnotetext{
Huimin Yan

hmyan@wh.iov.cn

$\triangle$ You Shang

you_shanghust@163.com

$\triangle$ Chaolin Huang

chaolin2020@163.com

1 Joint Laboratory of Infectious Diseases and Health, Wuhan Institute of Virology and Wuhan Jinyintan Hospital, Wuhan Institute of Virology, Center for Biosafety Mega-Science, Chinese Academy of Sciences (CAS), Wuhan 430023, China

2 State Key Laboratory of Virology, Wuhan Institute of Virology, Center for Biosafety Mega-Science, CAS, Wuhan 430071, China

3 Center for Translational Medicine, Jinyintan Hospital, Wuhan 430023, China
}

$\mathrm{CD}^{+} \mathrm{T}$ cell responses in an asymptomatic SARS-CoV-2 infected case.

A man in 30s of Hubei resident, who had traveled to Thailand from Wuhan around mid-January, 2020, was tested positive for SARS-CoV-2 upon return to Wuhan on late March and transferred to Wuhan Jinyintan Hospital for isolation. SARS-CoV-2 nucleotide was detected again at days 1-2 in sputum and/or nasopharyngeal swab samples but was undetectable since d5 (Fig. 1A and Supplementary Table S1). SARS-CoV-2-binding IgM was presented in plasma since $\mathrm{d} 7$, while $\mathrm{IgG}$ remained undetectable at all detected time points (Fig. 1A). These results implied that the man was still at the early stage of virus infection at the time of admission. At day 14 post hospitalization, the man was discharged to a designated hotel for another 14-dayisolation. Within the 28-day follow-up, the man presented neither clinical symptom nor CT abnormality (Supplementary Fig. S1, Supplementary Video S1). Taken together, this man was an asymptomatic SARS-CoV-2 infected individual.

4 Joint Laboratory of Infectious Diseases and Health, Wuhan Institute of Virology and Wuhan Jinyintan Hospital, Wuhan Jinyintan Hospital, Wuhan 430023, China

5 Department of Critical Care Medicine, Union Hospital, Tongji Medical College, Huazhong University of Science and Technology, Wuhan 430030, China

6 Department of Laboratory Medicine, Maternal and Child Health Hospital of Hubei Province, Tongji Medical College, Huazhong University of Science and Technology, Wuhan 430070, China

7 University of Chinese Academy of Sciences, Beijing 100049, China 


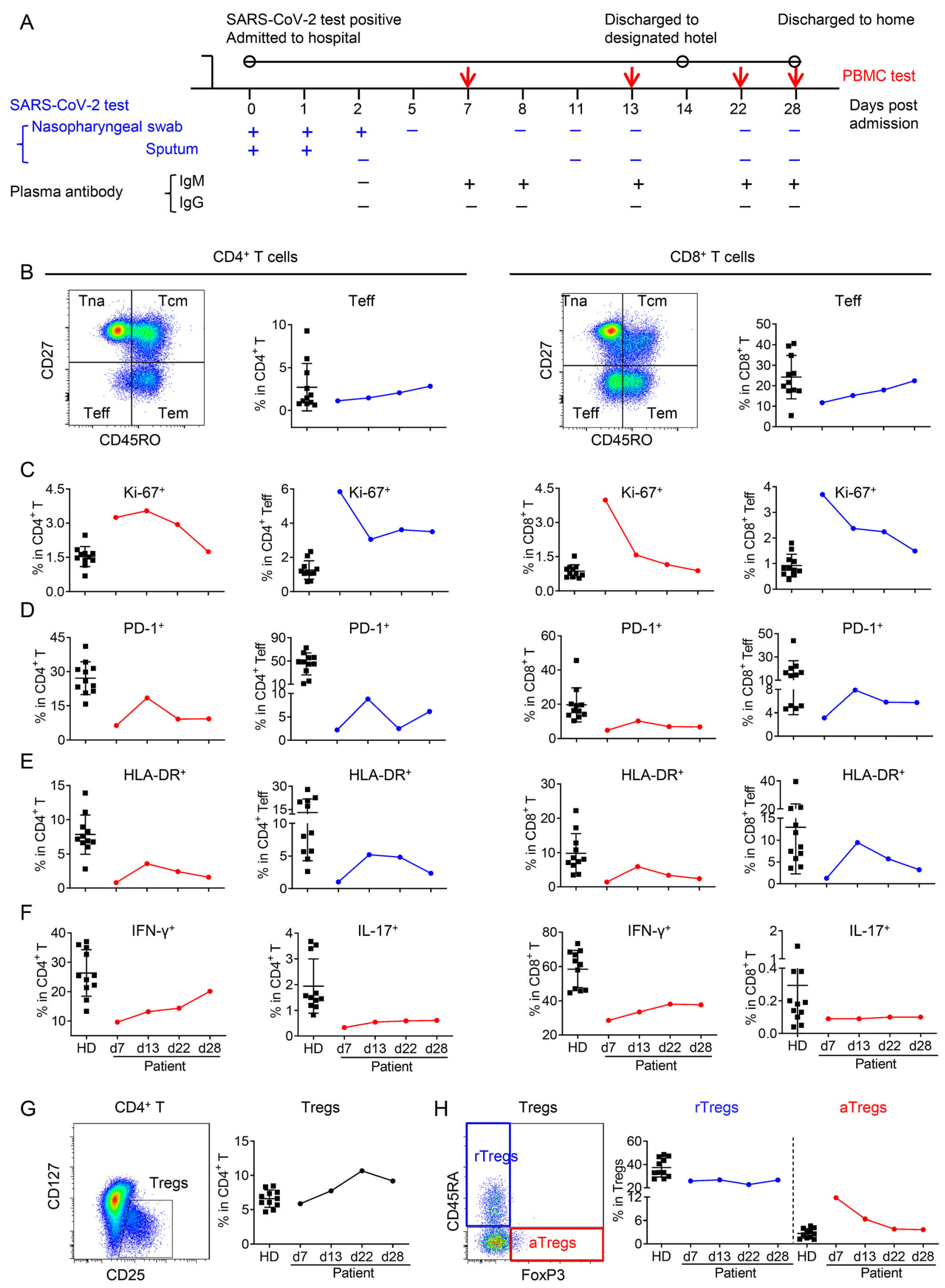


4 Fig. 1 T cell responses in PBMCs of the asymptomatic patient during SARS-CoV-2 infection. A Timeline of the study. SARS-CoV-2 infection was detected by qRT-PCR in nasopharyngeal swab, sputum, and by RBD-specific plasma IgM, IgG using colloidal gold strips. Peripheral blood was collected at the indicated time point post hospitalization for $\mathrm{T}$ cell response analysis. B-H T cell responses in PBMCs of the asymptomatic patient and healthy donors (HD, $\mathrm{n}=11)$. $\mathbf{B}-\mathbf{E}$ differentiation, proliferation and activation of $\mathrm{T}$ cells. B Frequencies of effector $\mathrm{T}$ cells (Teff) in $\mathrm{CD}^{+}{ }^{+}$or $\mathrm{CD}^{+} \mathrm{T}$ cells. Gating strategies of the naïve (Tna, $\mathrm{CD} 45 \mathrm{RO}^{-} \mathrm{CD} 27^{+}$), central memory $\left(\mathrm{Tcm}, \mathrm{CD} 45 \mathrm{RO}^{+} \mathrm{CD} 27^{+}\right)$, effector memory (Tem,

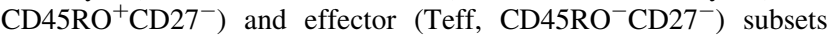
were shown as left panels. $\mathbf{C}-\mathbf{E}$ Frequencies of Ki-67 ${ }^{+}(\mathbf{C}), \mathrm{PD}-1^{+}$ (D) or HLA-DR ${ }^{+}(\mathbf{E})$ cells in $\mathrm{CD} 4^{+}$or $\mathrm{CD} 8^{+} \mathrm{T}$ cells of the patient and in that of HD. F After ex vivo stimulation by PMA/Ionomycin for $4.5 \mathrm{~h}$ in the presence of BFA and monensin, the production of IFN- $\gamma$ and $\mathrm{IL}-17$ by $\mathrm{CD} 4^{+}$or $\mathrm{CD}^{+} \mathrm{T}$ cells were analyzed by intracellular cytokine staining and flow cytometry. G-H Frequencies of Treg and Treg subsets. G Gating strategy and the frequency of $\mathrm{CD} 25^{+} \mathrm{CD} 127^{-}$ Tregs in $\mathrm{CD}^{+}{ }^{+} \mathrm{CD} 8^{-} \mathrm{CD} 4^{+} \mathrm{T}$ cells. $\mathbf{H}$ Gating strategies for Treg subsets and the frequencies of resting Treg cells (rTregs,

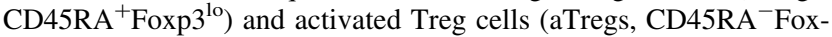
$\mathrm{p} 3^{\text {hi }}$ ) in Tregs.

During the follow-up period, $\mathrm{T}$ cell responses of this case were assayed by flow cytometry analysis of the fresh peripheral blood nonnuclear cells (PBMCs). Cell counts of total lymphocytes, $\mathrm{CD} 4^{+} \mathrm{T}$ cells, $\mathrm{CD}^{+} \mathrm{T}$ cells as well as the ratio of $\mathrm{CD}^{+} / \mathrm{CD}^{+} \mathrm{T}$ cells maintained at normal level (Supplementary Fig. S2). Further analysis on the differentiation of $\mathrm{CD}^{+}$and $\mathrm{CD}^{+} \mathrm{T}$ cells showed a significant and gradual increase of effector $\mathrm{T}$ cells $\left(\mathrm{CD} 45 \mathrm{RO}^{-} \mathrm{CD} 27^{-}\right.$, Teff) in both $\mathrm{CD}^{+}$and $\mathrm{CD}^{+} \mathrm{T}$ cells (Fig. 1B). The frequencies of naïve $\mathrm{T}$ cells $\left(\mathrm{CD} 45 \mathrm{RO}^{-} \mathrm{CD} 27^{+}\right.$, Tna), central memory $\mathrm{T}$ cells $\left(\mathrm{CD} 45 \mathrm{RO}^{+} \mathrm{CD} 27^{+}, \mathrm{Tcm}\right)$ in either $\mathrm{CD}^{+}$ or $\mathrm{CD}^{+} \mathrm{T}$ cells were not significantly changed, while the effector memory subset $\left(\mathrm{CD} 45 \mathrm{RO}^{+} \mathrm{CD} 27^{-}\right.$, Tem) were slightly increased (Supplementary Figs. S3A, S4A). In consistent with the kinetics of $\mathrm{T}$ cell differentiation, proliferation of $\mathrm{T}$ cells (assessed by the frequency of transcription factor $\mathrm{Ki}-67^{+}$), was much higher than that of healthy donors (HD) at $\mathrm{d} 7$ in both $\mathrm{CD}^{+}{ }^{+}$and $\mathrm{CD}^{+} \mathrm{T}$ cells. The higher frequency of $\mathrm{Ki}-67^{+}$cells lasted until d22 in $\mathrm{CD}^{+}{ }^{+} \mathrm{T}$ cells, while rapidly decreased to baseline at $\mathrm{d} 13$ in $\mathrm{CD}^{+}$T cells (Fig. 1C). The activation of $\mathrm{CD}^{+}$and $\mathrm{CD}^{+}$ $\mathrm{T}$ cells, determined as the percentage of PD- ${ }^{+}, \mathrm{HLA}-\mathrm{DR}{ }^{+}$ or $\mathrm{CD}_{3} 8^{+} \mathrm{HLA}_{-\mathrm{DR}}{ }^{+}$, were lower than the low limit of HD at $\mathrm{d} 7$, peaked at $\mathrm{d} 13$, and gradually decreased to a low level that was comparable as the beginning (Fig. 1D, 1E, Supplementary Fig. S5). The activation and proliferation of each differentiated subsets (Teff, Tna, Tcm, Tem) of CD4 ${ }^{+}$ or $\mathrm{CD}^{+} \mathrm{T}$ cells all showed the similar trend as the parent populations (Fig. 1C-1E, Supplementary Figs. S3, S4).

Then we examined the function potential of $\mathrm{CD}^{+}$and $\mathrm{CD}^{+} \mathrm{T}$ cells by stimulating PBMCs with polyclonal stimulator PMA and Ionomycin as previously described
(Knudson et al. 2015; Chang et al. 2019; Mazzoni et al. 2020; Zheng et al. 2020). Notably lower frequencies of IFN- $\gamma$ producing $\mathrm{CD}^{+}$(Th1) and $\mathrm{CD}^{+} \mathrm{T}$ cells (Tc1) were detected at $\mathrm{d} 7$, compared to those of HD. Although the frequencies of Th1 and Tc1 cells gradually increased from d7 to d28, Tc1 was still lower than that of HD at d28 (Fig. 1F). While kept in the normal range, IL-4 producing $\mathrm{CD}^{+}{ }^{+} \mathrm{T}$ cells (Th2) gradually increased from $\mathrm{d} 7$ to $\mathrm{d} 22$ then dropped to the baseline at $\mathrm{d} 28$ (Supplementary Fig. S6C). In contrast, frequency of IL-17 producing CD4 ${ }^{+}$ $\mathrm{T}$ cells (Th17) maintained at remarkably lower level than that in HD, without significant increase in all the tested time points. The IL- 4 or IL- 17 producing $\mathrm{CD}^{+}$cells were very rare, and with no significant changes (Supplementary Fig. S6D, Fig. 1F).

According to the expression of FoxP3 and CD45RA, regulatory T cells (Tregs, $\mathrm{CD} 3^{+} \mathrm{CD} 8^{-} \mathrm{CD} 4^{+} \mathrm{CD} 127^{-} \mathrm{CD} 25^{+}$) are classified into two suppressive subsets: a slight inhibitory CD45RA ${ }^{+}$FoxP3 $^{\text {lo }}$ resting Treg cells (rTregs) and a stronger inhibitory CD45 $\mathrm{RA}^{-}{ }^{-}$oxP3 ${ }^{\text {hi }}$ activated Treg cells (aTregs) (Miyara et al. 2009). The frequency of Tregs gradually increased since $d 7$, peaked at a much higher level than that of HD at d22, then slightly decreased at d28 (Fig. 1G). The composition of aTregs was much higher than that in $\mathrm{HD}$ at $\mathrm{d} 7$, then gradually decreased to normal range at $\mathrm{d} 22$, though the rTregs maintained at a sustained level as HD (Fig. 1H). CTLA4 is one of the most important co-inhibitory molecules expressed by Tregs. As shown in Supplementary Fig. S7, The dynamics of CTLA4 ${ }^{+}$in total Tregs and the two subsets were similar, in which the CTLA $4^{+}$population peaked at d13 and then dropped but without significant changes compared with HD.

Collectively, our study provides novel contributions to understanding the kinetics of $\mathrm{T}$ cell responses in an asymptomatic infection case. Although T cells counts were normal, the activation, frequency and function of $\mathrm{T}$ cell subsets were aberrant in this case. Specifically, suppressed activation of $\mathrm{T}$ cells, reduction of $\mathrm{Th} 1$ cells and elevation of aTregs were observed at early stage. Moreover, lower frequencies of Th17 and Tc1 cells were detained even at $\mathrm{d} 28$, when the SARS-CoV-2 virus had already become undetectable over 3 weeks. Our data suggested that the function potential of T cells especially Th17 and Tc1 was suppressed in the asymptomatic patient. Nevertheless, there is possibility that the active status of $\mathrm{T}$ cells by acute viral infection itself might make the $\mathrm{T}$ cells hypo-responsive to the polyclonal stimulator, PMA/ionomycin. If this is the case, the changing tendencies of different functional molecules such as IFN- $\gamma$ and IL-17 should be much more similar. However, in our study, the longitudinal curve of different functional molecules showed differential responses, which suggested limited interference of viral activation would be added on the effects by PMA/ionomycin 
stimulation. Additionally, previous studies also showed that the activation of $\mathrm{T}$ cells does not lead to hypo-response to PMA/ionomycin polyclonal stimulation (Wu et al. 2015; Chen et al. 2019).

The elevation of aTregs accompanying with the low activation and suppressed function of T cells at early stage of this asymptomatic case, suggested that aTregs might take part in the suppression of the activation and function of $\mathrm{T}$ cells. These $\mathrm{T}$ cell response characteristics should be confirmed further in larger cohorts of people with asymptomatic SARS-CoV-2 infection.

$\mathrm{T}$ cell responses in this asymptomatic case showed some similarity such as Th1 and Tc1 reduction as well as some differences compared to those reported in the symptomatic cases. Different from this asymptomatic case, significant decrease of $\mathrm{T}$ lymphocytes, lower levels of Tregs and remarkable activation of the $\mathrm{CD}^{+}$and $\mathrm{CD}^{+}{ }^{+} \mathrm{T}$ cells was reported in the symptomatic COVID-19 cases (Chen et al. 2020; Liu et al. 2020; Mazzoni et al. 2020; Qin et al. 2020; Thevarajan et al. 2020). The previous reports together with ours pointed out the complicated interactions between viral infection, $\mathrm{T}$ cell responses and clinical outcomes, which requires more intensive studies to clarify the role of $\mathrm{T}$ cell responses in the control and immunopathology of SARSCoV-2 infection.

Acknowledgements We thank the patient and healthy donors involved in this study.

\section{Compliance with Ethical Standards}

Conflict of interest All authors declare that they have no conflict of interest.

Study Approval This study was reviewed and approved by the Medical Ethical Committee of Wuhan Jinyintan Hospital (Approval No. KY-2020-47.01). Written informed consent was obtained from the patient and the healthy donors.

\section{References}

Black JRM, Bailey C, Przewrocka J, Dijkstra KK, Swanton C (2020) COVID-19: the case for health-care worker screening to prevent hospital transmission. Lancet 395:1418-1420

Chang KM, Traum D, Park JJ, Ho S, Ojiro K, Wong DK, Wahed AS, Terrault NA, Khalili M, Sterling RK, Janssen HLA, Shuhart MC, Lau DT, Roberts LR, Johnson GS, Kaplan DE, Betts MR, Lee WM, Lok ASF (2019) Distinct phenotype and function of circulating Vdelta ${ }^{1+}$ and Vdelta ${ }^{2+}$ gammadelta T-cells in acute and chronic hepatitis B. PLoS Pathog 15:e1007715

Chen PY, Wu CY, Fang JH, Chen HC, Feng LY, Huang CY, Wei KC, Fang JY, Lin CY (2019) Functional change of effector tumorinfiltrating $\mathrm{CCR}^{(+)} \mathrm{CD} 38^{(+)} \mathrm{HLA}-\mathrm{DR}{ }^{(+)} \mathrm{CD} 8^{(+)} \mathrm{T}$ cells in glioma microenvironment. Front Immunol 10:2395

Chen G, Wu D, Guo W, Cao Y, Huang D, Wang H, Wang T, Zhang X, Chen H, Yu H, Zhang M, Wu S, Song J, Chen T, Han M, Li S, Luo X, Zhao J, Ning Q (2020) Clinical and immunological features of severe and moderate coronavirus disease 2019. J Clin Invest 130:2620-2629

Knudson CJ, Hartwig SM, Meyerholz DK, Varga SM (2015) RSV vaccine-enhanced disease is orchestrated by the combined actions of distinct $\mathrm{CD}^{4} \mathrm{~T}$ cell subsets. PLoS Pathog 11:e1004757

Liu J, Li S, Liang B, Wang X, Wang H, Li W, Tong Q, Yi J, Zhao L, Xiong L, Guo C, Tian J, Luo J, Yao J, Pang R, Shen H, Peng C, Liu T, Zhang Q, Wu J, Xu L, Lu S, Wang B, Weng Z, Han C, Zhu H, Zhou R, Zhou H, Chen X, Ye P, Zhu B, Wang L, Zhou W, He S, He Y, Jie S, Wei P, Zhang J, Lu Y, Wang W, Zhang L, Li L, Zhou F, Wang J, Dittmer U, Lu M, Hu Y, Yang D, Zheng $X$ (2020) Longitudinal characteristics of lymphocyte responses and cytokine profiles in the peripheral blood of SARS-CoV-2 infected patients. EBioMedicine 55:102763

Mazzoni A, Salvati L, Maggi L, Capone M, Vanni A, Spinicci M, Mencarini J, Caporale R, Peruzzi B, Antonelli A, Trotta M, Zammarchi L, Ciani L, Gori L, Lazzeri C, Matucci A, Vultaggio A, Rossi O, Almerigogna F, Parronchi P, Fontanari P, Lavorini F, Peris A, Rossolini GM, Bartoloni A, Romagnani S, Liotta F, Annunziato F, Cosmi L (2020) Impaired immune cell cytotoxicity in severe COVID-19 is IL-6 dependent. J Clin Invest. https://doi.org/10.1172/JCI138554

Miyara M, Yoshioka Y, Kitoh A, Shima T, Wing K, Niwa A, Parizot C, Taflin C, Heike T, Valeyre D, Mathian A, Nakahata T, Yamaguchi T, Nomura T, Ono M, Amoura Z, Gorochov G, Sakaguchi S (2009) Functional delineation and differentiation dynamics of human $\mathrm{CD}^{4+} \mathrm{T}$ cells expressing the FoxP3 transcription factor. Immunity 30:899-911

Pan X, Chen D, Xia Y, Wu X, Li T, Ou X, Zhou L, Liu J (2020) Asymptomatic cases in a family cluster with SARS-CoV-2 infection. Lancet Infect Dis 20:410-411

Qin C, Zhou L, Hu Z, Zhang S, Yang S, Tao Y, Xie C, Ma K, Shang K, Wang W, Tian DS (2020) Dysregulation of immune response in patients with COVID-19 in Wuhan, China. Clin Infect Dis. https://doi.org/10.1093/cid/ciaa248

Thevarajan I, Nguyen THO, Koutsakos M, Druce J, Caly L, van de Sandt CE, Jia X, Nicholson S, Catton M, Cowie B, Tong SYC, Lewin SR, Kedzierska K (2020) Breadth of concomitant immune responses prior to patient recovery: a case report of non-severe COVID-19. Nat Med 26:453-455

Wu C, Goodall JC, Busch R, Gaston JS (2015) Relationship of CD146 expression to secretion of interleukin (IL)-17, IL-22 and interferon-gamma by $\mathrm{CD}^{4(+)} \mathrm{T}$ cells in patients with inflammatory arthritis. Clin Exp Immunol 179:378-391

Zheng M, Gao Y, Wang G, Song G, Liu S, Sun D, Xu Y, Tian Z (2020) Functional exhaustion of antiviral lymphocytes in COVID-19 patients. Cell Mol Immunol 17:533-535 